\section{Double mitral apparatus}

\section{Clinical image}

Doubling the mitral valve is a rare congenital heart defect. It is Characterized by the presence of two smaller mitral apparatus, Generally attachment system, is located in the anterior mitral cusp, separated by a fibrous tissue. ${ }^{1}$ The explanation of the change in the embryological development is accepted by an abnormality in the development between the ventral or dorsal medial tubers pad with side. $^{2,3}$

Usually they associated with aortic aneurysm, bicuspid aortic valve, aortic coarctation, subaortic stenosis, patent ductus arteriosus, abnormal interatrial and interventricular septum. They may evolve failure and / or mitral stenosis. (Figures 1-4)

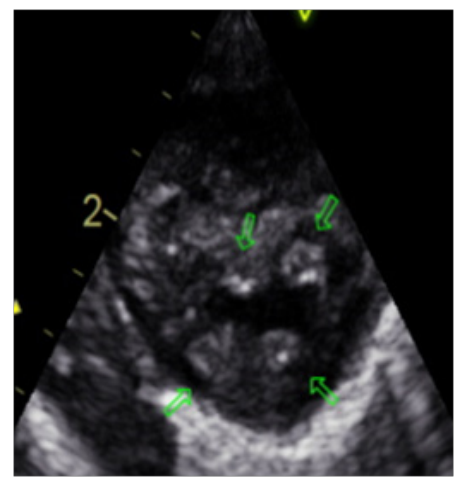

Figure I Parasternal short axis.

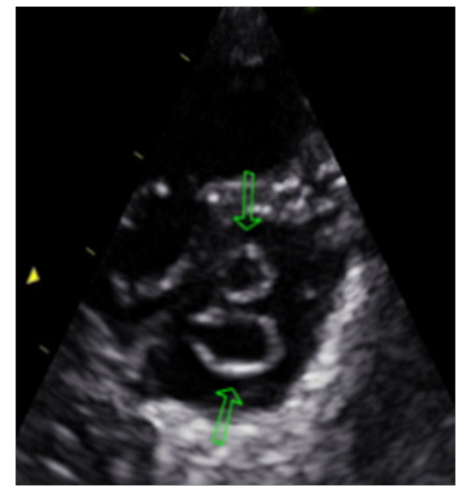

Figure 2 Parasternal short axis. Presence of 4 muscle Papillary. Double mitral orifice.

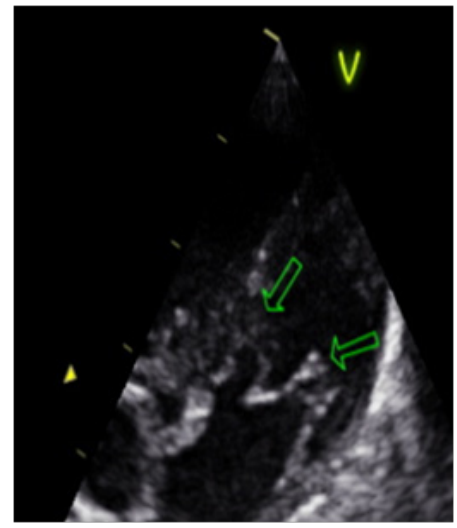

Figure 3 Long Axis 5 cameras.
Volume II Issue 5 - 2018

Maria Laura Vidales,' Paola Vilche, ${ }^{2}$ Daghero Fernando, ${ }^{3}$ Marcelo Urinovsky, ${ }^{3}$ Miguel Angel Tibaldi ${ }^{4}$

'Fellow of echocardiography, Sanatorio Allende Cerro branch, Argentina

${ }^{2}$ Degree in radiology, echocardiography technique, Sanatorium Allende Cerro branch, Argentina

${ }^{3}$ Cardiologist staff, Sanatorium Allende branch Cerro, Córdoba, Argentina.

${ }^{4}$ Cardiologist staff, chief of cardiology service, Sanatorio Allende Cerro branch, Córdoba, Argentina

Correspondence: Maria Laura Vidales, Fellow of echocardiography, Sanatorio Allende Cerro branch, Argentina, Email lau_vidales@hotmail.com

Received: August 22, 2018 | Published: September 05, 2018

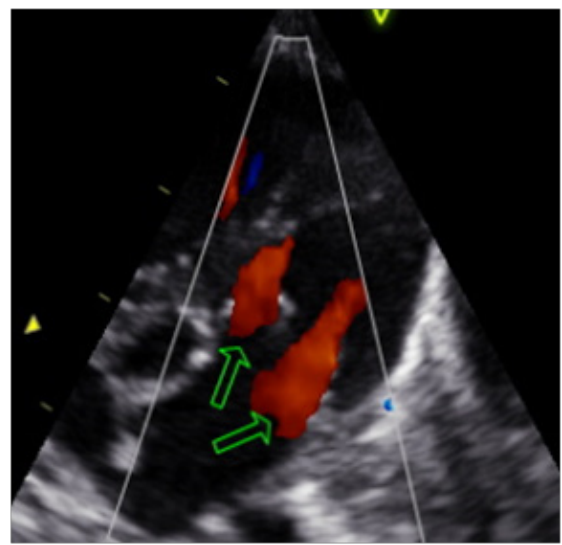

Figure 4 Long Axis 5 cameras. Double mitral apparatus. Mitral presence of two flows.

Echocardiography is essential for the diagnosis, treatment and follow-up..$^{4-5}$ We present a newborn preterm, low birth weight, the doppler echocardiogram applying for breath. echodopplercardiogram is performed evidencing patent foramen ovale with shunt from left to right, moderate muscle septal shunt left to nonsignificant right, double mitral apparatus, permeable, no records diastolic gradient and mild impairment of both, patent ductus arteriosus, big, not restrictive and overactive.

\section{Acknowledgements}

None.

\section{Conflict of interest}

The author declares that there is no conflict of interest.

\section{References}

1. N Ciampani, D Vecchiola, C Silenzi, et al. The tensor apparatus in double-orifice mitral valve: Interpretation of echocardiographic findings. 
J Am Soc Echocardiogr. 1997;10(8):869-873.

2. E. Wigle. Duplication of the mitral valve. Br Heart J. 1957;19(2):296300 .

3. A Banerjee, $\mathrm{T}$ Kohl, $\mathrm{N}$ Silverman. Echocardiographic evaluation of congenital mitral valve anomalies in children. Am J Cardiol. 1995;76(17):1284-1291.
4. J Amano, A Suzuki. Surgical treatment of duplication of the mitral valve. J Cardiovasc Surg (Torino). 1986;27(3):323-327.

5. G Jensen, T Smith, M Flores. Repair of a mitral valve in a patien duplicate ascending aortic aneurysm With bicuspid aortic valve and. Ann Thorac South.2014;97(3):e67-e69. 